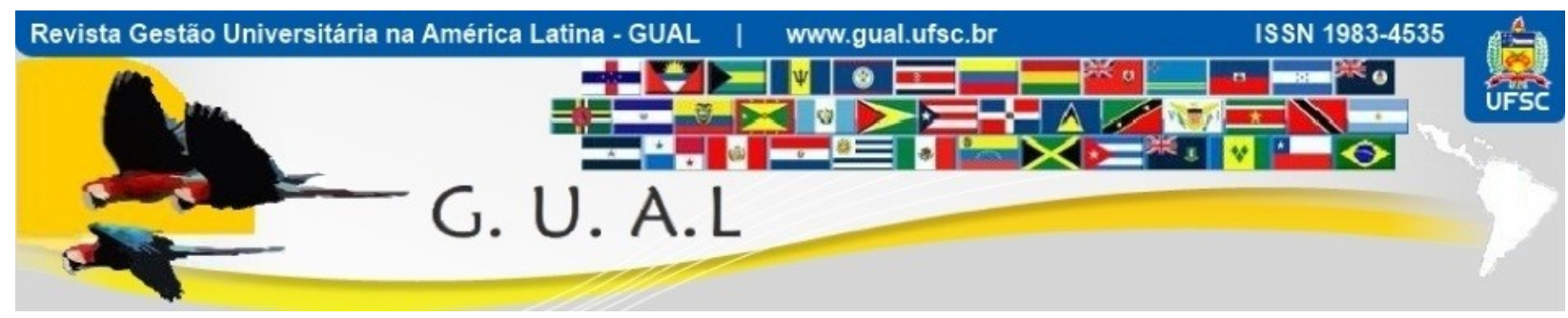

DOI: http://dx.doi.org/10.5007/1983-4535.2013v6n1p1

\title{
DESAFIOS DA GESTÃO EM INSTITUIÇÕES DE ENSINO SUPERIOR: UM ESTUDO DE CASO A PARTIR DA PERCEPÇÃO DE DIRETORES DE CENTRO DE UMA IES PÚBLICA DO SUL DO BRASIL
}

\section{CHALLENGES OF MANAGEMENT IN INSTITUTIONS OF HIGHER EDUCATION: A CASE STUDY FROM THE PERCEPTION OF CENTER DIRECTORS OF AN PUBLIC IES IN THE SOUTHERN OF BRAZIL}

Márcia Regina Bronnemann, Mestre Universidade Regional de Blumenau - FURB broneman@gmail.com

Recebido em 11/setembro/2012

Aprovado em 03/dezembro/2012

Sistema de Avaliação: Double Blind Review 


\title{
RESUMO
}

Esta pesquisa objetivou analisar os desafios de gestão a partir da percepção de diretores de centro de uma instituição de ensino superior (IES) pública do sul do Brasil no tocante a conhecimentos; avaliações de outras pessoas; tempo disponível; comprometimento dos subordinados; gestão de divergências; burocracia e centralização; e cuidados éticos. Realizouse um estudo de caso qualitativo com coleta de dados por meio de entrevistas em profundidade com sete diretores de centro a partir de um roteiro com questões abertas, cujas respostas se submeteram à análise de conteúdo. Os principais desafios enfrentados pelos diretores de centro estão relacionados à ausência de conhecimento prévio sobre a função e sobre aspectos de gestão; ao tempo disponível para o cargo em relação às atividades que necessitam ser realizadas; e à gestão de divergências relacionais de subordinados, administrativas e pessoais. Espera-se que este estudo possa contribuir para a gestão universitária ao apontar alguns dos desafios enfrentados por gestores universitários no exercício de sua função, auxiliando-os, assim, a melhorar seus processos de preparação, bem como auxiliar as IES no acompanhamento desses profissionais. Além disso, acredita-se que se possa contribuir com a área de conhecimento ao identificar diferentes desafios e, portanto, diferentes possibilidades de temas de pesquisa em gestão universitária.

Palavras-chave: Gestão universitária. Desafios. Diretores de centro.

\begin{abstract}
This research aimed to analyze the management challenges from the perception of Center Directors of a higher education institution (IES) in the South of Brazil with regard to knowledge; evaluations of others; time available; commitment of subordinates; management of differences; bureaucracy and centralization; and ethical actions. A qualitative case study with data collection by means of in-depth interviews with seven Center Directors from a screenplay with open questions, whose answers underwent content analysis. The main challenges faced by the directors of the Center are related to the absence of prior knowledge about the function and management aspects; the time available for the position in relation to the activities that need to be carried out; and management of relational differences of subordinates, administrative and personal. It is hoped that this study can contribute to the University Management to point out some of the challenges faced by University managers in the exercise of its function, helping them improve their processes of preparation, as well as assist the HIES in the monitoring of these professionals. In addition, it is believed that it can contribute to the area of knowledge to identify different challenges and, therefore, different possibilities of research topics in university management.
\end{abstract}

Keywords: University management. Challenges. Center Directors. 


\section{INTRODUÇÃO}

As IES são complexas e diferentes de outros tipos de organizações em virtude de sua estrutura, sua organização e seus objetivos serem diferenciados. Atualmente, essas instituições enfrentam diversos desafios, como acirramento da concorrência, exigências legais e normas de entidades reguladoras.

Para enfrentar os desafios, as IES necessitam ampliar sua eficácia gerencial, o que demanda habilidades de seus diretores para lidar com diferentes situações. Contudo, esses gestores universitários, normalmente docentes, necessitam conciliar atividades acadêmicas e de gestão, o que desencadeia situações adversas em suas atividades cotidianas (MARRA; MELO, 2003). Além disso, os gestores universitários normalmente não possuem, antes de assumirem o cargo, conhecimento gerencial, de liderança e de gestão de pessoas, o que pode acarretar diferentes dificuldades (SILVA; MORAES, 2003).

No contexto apresentado, verifica-se a relevância de estudar as dificuldades enfrentadas pelos gestores universitários no exercício do cargo. O problema de pesquisa, portanto, pode ser descrito por meio da seguinte questão: Quais os principais desafios enfrentados por diretores de centro no exercício da função? Com essa pesquisa, pretendeu-se contribuir para a melhoria do desempenho das atividades desses profissionais, ampliando a eficácia das IES e a qualidade do ensino oferecido.

Assim, esta pesquisa teve por objetivo analisar os desafios de gestão a partir da percepção de diretores de centro de uma IES pública do sul do Brasil no tocante a conhecimentos; avaliações de outras pessoas; tempo disponível; comprometimento dos subordinados; gestão de divergências; burocracia e centralização; e cuidados éticos.

Este artigo está organizado em quatro seções, além desta introdução: na próxima, temse a base teórica sobre gestão universitária; na terceira, descrevem-se os procedimentos metodológicos adotados; na quarta, descrevem-se os resultados obtidos; e, na última, tecem-se as considerações finais.

\section{BASE TEÓRICA}

As IES são consideradas organizações complexas, de acordo com Schmitz e Bernandes (2008), porque executam tarefas múltiplas (ensino, pesquisa e extensão) por meio de uma metodologia única; têm como matéria-prima o conhecimento, buscando qualificar os profissionais para o desenvolvimento da sociedade; e possuem um modelo de gestão político, 
colegiado, burocrático e, muitas vezes, anárquico. Andrade (2002), por sua vez, afirma que as IES são consideradas organizações complexas porque possuem as seguintes características: relativa autonomia dos profissionais; multiplicidade de objetivos; fragmentação da estrutura; complexidade tecnológica; e disseminação das decisões ao longo de um grande número de unidades e de atores.

Diante do apresentado, destaca-se que essas características das IES podem tornar o exercício de sua gestão mais difícil e complexo. Nesse sentido, para Walter e Meyer Júnior (2010), as IES igualmente podem ser consideradas como sistemas frouxamente articulados, ou seja, possuem uma liderança mais difusa, sendo que cada unidade representa um sistema parcialmente autônomo de ação e cada pessoa possui relativa autonomia em suas atividades (WEICK, 1982). Como consequência, tanto as decisões são divulgadas quanto as divergências são negociadas em ritmos mais lentos, tornando o sistema menos tangível e mais difícil de ser administrado. Além disso, as avaliações de desempenho são frequentemente informais, subjetivas e desarticuladas (WALTER; MEYER JÚNIOR, 2010).

Walter e Meyer Júnior (2010) também apontam que, normalmente, professores são nomeados ou eleitos para cargos de gestão sem terem conhecimento ou habilidades para o exercício dessa função, de forma que o aprendizado ocorre, costumeiramente, ao longo da atuação por meio da experiência com acertos e erros (DOMINGUES et al., 2009).

Esse aprendizado por meio da experiência na função, no estudo realizado por Silva e Moraes (2003), ocorreu em cinco fases: natureza política da função; administração de conflitos e de diferenças; obtenção do envolvimento e comprometimento das pessoas; ambiente da IES; administração de recursos em um ambiente caracterizado por normas e burocracia. Os autores destacam, ainda, que a área de aprendizagem considerada mais importante pelos gestores para seu sucesso no cargo foi a habilidade de lidar com os conflitos e as diferenças entre pessoas e grupos.

O contexto das IES fica mais complexo ao se considerar estudos segundo os quais os gestores normalmente possuem pouco tempo para se dedicar ao cargo, visto que sua carga horária destinada à gestão é reduzida e necessitam conciliar seu tempo de permanência na IES com atividade de ensino, pesquisa e extensão (DOMINGUES et al., 2009).

Além dos aspectos técnicos e relacionais abrangidos por seus cargos, os gestores universitários também necessitam estar atentos para os aspectos éticos de cada decisão ou ação realizada. Como destaca Cenci (2009, p. 12), a ética auxilia no "exercício da 
transparência, da responsabilidade e da democracia e, sobretudo, na superação de modelos autoritários e tecnocráticos de gestão" das IES. O autor aponta, ainda, que é importante que as IES fomentem valores de justiça, igualdade, democracia e solidariedade em suas práticas.

Diante do apresentado nesta revisão de literatura, é possível elencar alguns dos principais desafios que os gestores universitários podem enfrentar no exercício de sua função (quadro 1).

\begin{tabular}{|c|c|}
\hline Desafios & Base teórica \\
\hline $\begin{array}{l}\text { Conhecimento e } \\
\text { habilidades }\end{array}$ & $\begin{array}{l}\text { Professores são nomeados ou eleitos para cargos de gestão sem terem conhecimento ou } \\
\text { habilidades para o exercício dessa função (WALTER; MEYER JÚNIOR, 2010). }\end{array}$ \\
\hline $\begin{array}{l}\text { Avaliações de } \\
\text { desempenho }\end{array}$ & $\begin{array}{l}\text { As avaliações de desempenho são, frequentemente, informais, subjetivas e } \\
\text { desarticuladas (WALTER; MEYER JÚNIOR, 2010). }\end{array}$ \\
\hline $\begin{array}{l}\text { Tempo para } \\
\text { atividades }\end{array}$ & $\begin{array}{l}\text { Os gestores possuem pouco tempo para as atividades de gestão e precisam conciliar seu } \\
\text { tempo na IES com as atividades de docência (DOMINGUES et al., 2009). }\end{array}$ \\
\hline $\begin{array}{l}\text { Comprometimento } \\
\text { dos subordinados }\end{array}$ & $\begin{array}{l}\text { Um dos aprendizados dos gestores ao longo do exercício da função é o de } \\
\text { envolvimento e comprometimento das pessoas da IES (SILVA; MORAES, 2003). }\end{array}$ \\
\hline $\begin{array}{c}\text { Gestão de } \\
\text { divergências }\end{array}$ & $\begin{array}{l}\text { A área de aprendizagem considerada mais importante para o sucesso dos gestores é a } \\
\text { capacidade de lidar com os conflitos e diferenças entre pessoas e grupos (SILVA; } \\
\text { MORAES, 2003). }\end{array}$ \\
\hline $\begin{array}{l}\text { Burocracia e } \\
\text { centralização }\end{array}$ & $\begin{array}{l}\text { As IES possuem um modelo de gestão político, colegiado e burocrático (SCHMITZ; } \\
\text { BERNANDES, 2008), caracterizando-se pela disseminação das decisões ao longo de } \\
\text { um grande número de unidades e de atores (ANDRADE, 2002). }\end{array}$ \\
\hline Ética & $\begin{array}{l}\text { A ética na gestão universitária favorece valores como justiça, igualdade, democracia e } \\
\text { solidariedade, assim como o exercício da responsabilidade, da transparência e da } \\
\text { democracia (CENCI, 2009). }\end{array}$ \\
\hline
\end{tabular}

Quadro 1 Principais desafios dos gestores universitários encontrados na base teórica deste estudo Fonte: Elaborado a partir da base teórica deste estudo.

A partir dos desafios apresentados no quadro 1, construíram-se o instrumento de coleta de dados empregado desta pesquisa e as categorias de análise.

\section{PROCEDIMENTOS METODOLÓGICOS}

Para atingir o objetivo deste estudo, optou-se por uma abordagem qualitativa de caráter descritivo-interpretativa, por meio de um estudo de caso único (STAKE, 1995) em uma IES pública do sul do Brasil. No que se refere à escolha desse caso, seguiram-se as orientações de Stake (1995), para quem o critério de maior importância consiste em maximizar o que se pode aprender por meio dele.

A opção por uma abordagem qualitativa de caráter descritivo-interpretativa deve-se à natureza dos fenômenos, do tipo de relação e da necessidade de descrever esses fenômenos e suas especificidades. 
A perspectiva temporal foi transversal, tendo sido a coleta de dados realizada por meio de entrevista aplicada a sete diretores de centro na gestão 2007-2010. Os centros pesquisados foram o Centro de Ciências Sociais Aplicadas (CCSA), Centro de Ciências da Educação (CSE), Centro de Ciências Exatas e Naturais (CCEN), Centro de Ciências Humanas e da Comunicação (CCHC), Centro de Ciências Jurídicas (CCJ), Centro de Ciências da Saúde (CES) e Centro de Ciências Tecnológicas (CCT).

Para tal, empregou-se um roteiro de entrevista com questões abertas relacionadas às categorias de análise escolhidas a partir da revisão de literatura:

a) conhecimentos: habilidades e conhecimentos importantes para o desempenho do cargo que foram obtidos anteriormente ou no decorrer das atividades de gestão (WALTER; MEYER JÚNIOR, 2010);

b) avaliações: análise e avaliações de outras pessoas da IES a respeito do desempenho do gestor no exercício da função (WALTER; MEYER JÚNIOR, 2010);

c) tempo: tempo disponível para realização das atividades vinculadas ao cargo, o que demanda a conciliação de tais atividades com as de ensino e outras (DOMINGUES et al., 2009);

d) comprometimento dos subordinados: disposição e comprometimento das pessoas subordinadas ao diretor no que se refere à realização das atividades da IES (SILVA; MORAES, 2003);

e) gestão de divergências: administração dos conflitos e divergências ocorridos entre os integrantes da IES subordinados ao diretor, buscando a resolução da situação e minimização dos prejuízos para a IES (SILVA; MORAES, 2003);

f) burocracia e centralização: concentração das decisões e informações no cargo responsável por cada nível e setor, bem como divulgação das informações de um nível hierárquico ao seu subsequente ao longo de toda a hierarquia (ANDRADE, 2002; SCHMITZ; BERNANDES, 2008);

g) ética: cuidados éticos nas decisões tomadas e procedimentos adotados pelos gestores (CENCI, 2009).

Gravaram-se as entrevistas em áudio e, posteriormente, se fez a transcrição na íntegra para a realização das análises.

Empregou-se a análise de conteúdo do tipo temática (BARDIN, 2002), de forma que se fez a leitura das entrevistas e se agruparam as dificuldades relatadas pelos gestores de acordo com as categorias de análise. A partir disso, realizou-se a apresentação dos resultados obtidos em cada categoria de forma descritiva com o auxílio de trechos das entrevistas. 
Na sequência, se fez a leitura das entrevistas e se agruparam as dificuldades relatadas pelos gestores de acordo com as categorias de análise. A partir disso, procedeu-se à análise de conteúdo do tipo temática (BARDIN, 2002), juntamente com a apresentação, de forma descritiva e com o auxílio de trechos das entrevistas, dos resultados obtidos em cada categoria.

\section{RESULTADOS}

Nesta seção, apresentam-se os resultados obtidos por meio das entrevistas com os diretores de centro organizados nas sete categorias de análise: conhecimento; avaliações; tempo; comprometimento dos subordinados; gestão de divergências; burocracia e centralização; e ética.

\subsection{O CASO ANALISADO}

A universidade pesquisada possui mais de 40 anos e está localizada no sul do Brasil. Caracterizada como autarquia municipal de regime especial, é mantida por uma fundação de direito público, possuindo autonomia didático-científica, administrativa e de gestão financeira e patrimonial.

Essa IES atende atualmente, no ano de 2012, a cerca de 15.000 alunos, distribuídos em seus 39 cursos de graduação e mais de 70 cursos de pós-graduação, sendo 7 mestrados e 2 doutorados. Também abrange uma escola de Ensino Médio e três institutos de pesquisa. $\mathrm{Na}$ extensão, oferece mais de 80 projetos, os quais realizam por ano, em média, 65.000 atendimentos à comunidade.

A estrutura hierárquica dessa universidade abrange dois conselhos (universitário; e ensino, pesquisa e extensão), reitoria, pró-reitoria, procuradoria, ouvidoria, controladoria, coordenadorias, unidade de Ensino Médio, unidades universitárias e órgãos suplementares. Nesta pesquisa, o interesse se voltou especificamente para as unidades universitárias que abrangem os sete centros de ensino da IES: Educação; Exatas e Naturais; Humanas e da Comunicação; Jurídicas; Saúde; Sociais Aplicadas; e Tecnológicas. Esses centros de ensino são unidades de administração setorial constituídas por um conjunto de conselhos de centro, direções de centro e departamentos de áreas afins.

Os diretores dos centros mencionados são três homens e quatro mulheres, todos com mais de 10 anos de atividades na universidade investigada e com experiência em cargos 
administrativos de outros níveis, como chefia de departamento e coordenação de curso. Um desses diretores possui formação na área de gestão, e os demais são professores em suas áreas de formação, além de que três deles estavam sendo reconduzidos ao cargo para o segundo mandato.

\subsection{CONHECIMENTOS IMPORTANTES PARA O EXERCÍCIO DO CARGO}

O fato de os diretores de centro não terem, normalmente, conhecimentos relacionados à gestão pode dificultar sua atuação em alguns aspectos, como aconteceu, por exemplo, no caso do sistema de controle de orçamento, citado por um entrevistado. Além desses conhecimentos técnicos, alguns diretores indicam desafios relacionados a habilidades de liderança e de gestão de pessoas. De acordo com Walter e Meyer Júnior (2010), isso ocorre porque professores são nomeados ou eleitos para cargos de gestão sem terem conhecimento ou habilidades para o exercício dessa função.

Nesse sentido, o fato de a IES ter o cargo de diretor de centro como eletivo, além do acúmulo da questão política e de gestão técnica, aumentou a necessidade de habilidade de liderança política, no sentido de representar sua área, precisando, para tanto, ter legitimidade, sem se esquecer da finalidade da universidade, que está vinculada ao ensino, pesquisa e extensão.

A inexperiência da gestão, segundo um dos entrevistados, "está vinculada a algumas tomadas de decisão que são difíceis, pelo fato de se ter pouca familiaridade com a situação administrativa". Além disso, muitas vezes, não são transmitidos aos novos diretores os conhecimentos relacionados ao contexto universitário da gestão anterior, o que, de certa forma, faz com que a nova gestão tenha que iniciar do ponto zero. Nessa direção, é possível ponderar que algumas tomadas de decisão encontram-se vinculadas à transição do cargo, a qual se encontra atrelada, segundo um dos entrevistados, à “inexperiência na área administrativa", uma vez que todos os diretores de centro participantes desta pesquisa, com exceção do diretor da área de Ciências Sociais Aplicadas, têm formação vinculada a sua área de atuação na condição de professor, e não de planejador.

Destaca-se que os novos diretores de centros, muitas vezes, não possuem a real noção da complexidade do cargo e do conhecimento necessário para o mesmo, apesar de as atribuições do cargo estarem em documentos escritos na IES. Isso, segundo esses diretores, na prática, se efetiva de forma bastante particular e aprofundada, visto que os documentos 
inerentes ao cargo estejam vinculados apenas a diretrizes e ao conhecimento que possuem os funcionários, os professores e os demais pares na IES.

De acordo com alguns diretores, "algumas decisões têm implicações diversas e, muitas vezes, as situações são apresentadas sem que as pessoas que decidem conheçam a fundo todo o processo e as consequências em relação à decisão serão vistas futuramente". Assim, se torna necessário buscar maiores informações com os pares, ou seja, com outros diretores, e mesmo com a equipe de trabalho, bem como a contribuição dos funcionários mais experientes, como, por exemplo, das secretárias e dos funcionários em geral, que estão há mais tempo na instituição.

Para outro diretor, uma forma de resolver esse problema está vinculada a tirar proveito dos pontos fortes, delegando algumas funções, conversando com as pessoas e conseguindo apoio.

Mais especificamente, destaca um diretor que, em um primeiro momento, sentiu-se com "certo despreparo na medida em que participava das reuniões e verificava o nível dos assuntos e a diversidade deles, sentindo-me despreparado em alguns aspectos", tecnicamente despreparado para tomar algumas decisões, a exemplo de trabalhar com conceitos econômicos financeiros. Ressalta-se que o diretor tem, entre suas funções, que gerir um orçamento, necessitando lidar, ainda, com dados contábeis, o que exige que entenda de economia, contabilidade e finanças, que vão muito além daquilo que esse profissional utiliza no cotidiano.

Após certo tempo no cargo, outro diretor participante da pesquisa admitiu que sente falta de conhecimento para resolver alguns problemas, como também visualiza que precisa de muitos outros conhecimentos para melhorar a qualidade do seu trabalho. Ainda segundo sesse diretor, houve diretores que resolveram esses problemas porque buscaram qualificação ou acabaram aprendendo na prática.

O mesmo diretor ratificou que, "quando se assume uma função, tem que se sentir em condições mínimas para assumir o cargo". Tem, porém, convicção de que, mesmo com condições de pleitear uma determinada posição, a IES "tem que dar amparo para suprir as deficiências para capacitar este profissional; uma vez que os objetivos são comuns". Nesse sentido, a instituição poderia fornecer condições para superar as dificuldades desse profissional, além de possibilitar-lhe desempenhar a sua função. 
O diretor de outra área relatou que "não tenho uma receita para lidar com todos esses problemas porque cada dia é um dia diferente, mas a maior parte destes problemas são cíclicos". A cada começo de semestre acadêmico, os problemas a serem enfrentados são os mesmos do semestre que terminou, e a experiência do passado contribui para a resolução desses problemas, se for levado em conta que existe uma rotina de trabalho estabelecida, ou seja, o diretor já sabe como utilizar o conhecimento instituído em benefício futuro. Nesse sentido, como observado por Domingues et al. (2009), os gestores costumam aprender ao longo de sua atuação por meio da experiência com acertos e erros.

\subsection{AVALIAÇÕES SOBRE SEU DESEMPENHO NO CARGO}

A principal dificuldade com as avaliações de seu desempenho, segundo um dos diretores entrevistados, está em ser "julgado" frequentemente, ou seja, que as pessoas "deduzam" se ele está indo bem ou mal, sob o ponto de vista daquilo que "elas" imaginam. Em outras palavras, é um padrão individual de julgamento, em que cada membro da IES avalia os diretores a partir de percepções subjetivas e descontextualizadas. A esse respeito, Walter e Meyer Júnior (2010) indicam que, em organizações frouxamente articuladas como as IES, as avaliações de desempenho são frequentemente informais, subjetivas e desarticuladas.

Como indica um dos diretores, ao representar as pessoas junto aos conselhos, mesmo que para defendê-las, as críticas aparecem: "Nem sempre o diretor é bem interpretado; por mais bem intencionado que sejam as pessoas, imaginam que o diretor poderia ter feito algo a mais".

Esse fato se torna mais acentuado quando o diretor traz uma notícia negativa. Passa, então, a administrar conflitos, "porque muitos professores não entendem o funcionamento da universidade, não conhecem como as receitas da instituição são administradas e que as despesas são permitidas pelo orçamento. Acreditam que, pela rentabilidade do centro, tudo é possível, uma vez que sua receita é maior que as demais áreas". O diretor conclui mencionando que "os professores acreditam que a universidade deve atender a todas as solicitações, independente da disponibilidade, sem levar em consideração a universidade como um todo, ou seja, observando todos os demais centros", existindo somente um julgamento desses profissionais, que visualizam apenas o seu centro de atuação. Nesse caso, de acordo com esse entrevistado, caberá ao diretor transmitir as decisões de forma a não ser 
julgado na condição de um profissional que não está defendendo os pontos de vista desses professores, e sim analisando a universidade como um todo.

Quanto ao julgamento do seu trabalho, esse mesmo diretor comentou que "o pessoal técnico-administrativo tem muita expectativa em relação aos gestores”, esperando, naturalmente, que o diretor exerça a liderança vista sob o conceito de ter respostas para tudo, capacidade para orientá-los e tomar a decisão correta. O diretor igualmente sugeriu que não é um gestor nato: "sou um professor e acabei tornando-me um gestor dentro da academia". Esse gestor, no caso, procura fazer o que considera ser o mais correto e permanecerá nesse entendimento enquanto alguém não questionar a sua postura, ou seja, todas as decisões tomadas dentro da IES acabarão sendo julgadas pelos profissionais que contribuíram e que colocaram esses diretores na condição de seus representantes.

\subsection{TEMPO PARA REALIZAÇÃO DAS DIFERENTES ATIVIDADES}

Com relação ao seu tempo, para um diretor entrevistado, "um dos problemas desse cargo está relacionado ao número de solicitações para reuniões e eventos que recebo". Mais da metade desses convites, esse diretor não consegue atender devido à coincidência de agenda, sendo que, geralmente, envia um representante do centro. Porém, os anfitriões reclamam dessa postura e comentam que, apesar de os convites terem sido feitos com antecedência, dificilmente são atendidos. Os órgãos da universidade, por sua vez, ao perceberem que o diretor raramente atende as suas solicitações, julgam tal atitude falta de consideração. O diretor conclui que, caso "atenda todas as solicitações, não terei tempo para trabalhar". Segundo o mesmo, não terá condições de planejar, inovar e desenvolver novos projetos, ou seja, ficaria vinculado apenas aos compromissos "sociais" da universidade.

Outro problema relacionado com o uso do tempo do diretor de centro está ligado à demanda para a produção científica. A academia exige que as pessoas ligadas a ela produzam com bastante frequência projetos de pesquisa e, para tanto, é necessário um tempo adicional para ler e escrever. O diretor acredita que precisa delegar algumas atividades para seus subordinados e, dessa forma, conseguir tempo para dedicar-se à produção científica.

Segundo um diretor, "outra atividade que exige dedicação constante e, dessa forma, demanda um tempo considerável, é a leitura das portarias editadas pela administração central". As portarias alteram as diretrizes da universidade. O diretor afirma que as leituras que faz são direcionadas praticamente ao cargo que exerce: "quando vou para casa no fim de 
semana, vou pensando como realizar isso, como fazer aquilo. Mas eu não vejo problemas, este é o ônus do cargo". Porém, dessa maneira, acaba por direcionar suas leituras apenas a esses conteúdos, não contemplando sua área de atuação.

O diretor de outro centro mencionou que "outro problema a ser observado é o fato de que sou profissional em atuação no mercado, porque não tenho dedicação exclusiva ao cargo de diretor de centro". Assim, o diretor está no cargo, mas também precisa conciliar as duas atividades simultaneamente, porque, quando deixar de ser diretor, voltará a atuar na sua área profissional mais intensivamente.

Nas atividades nas quais não pode estar presente, por estar em outro local, o diretor fica tranquilo, pois acaba sendo substituído pela vice-direção, considerando que ambos mantêm um excelente relacionamento profissional, o que facilita sua gestão. O mesmo já ocorria com a vice-direção de uma gestão anterior. "Durante sua atuação contribuiu em muito para resolução dos problemas do centro", completa o diretor. Nesse sentido, o professor em exercício espera que o próximo diretor do centro seja seu atual vice, em função de sua competência e envolvimento com as atividades.

O diretor afirmou que, quanto ao tempo disponível para as atividades, são 23 horas de administração setorial que, em sua opinião, são um absurdo se este ficar somente na sua sala esperando que as coisas aconteçam, porque a maioria das atividades não é de gabinete. A instituição possui convênios com algumas empresas da região, sendo que as reuniões para renovação são realizadas nesses locais e outras reuniões são realizadas fora do ambiente universitário. Essas são as dificuldades para manter um horário fixo. Todo semestre, o diretor é convocado para reuniões na universidade que são vinculadas ao conselho de centro, às próreitorias de ensino ou de administração, de pesquisa e à reitoria, "ou seja, têm que se observar que a universidade é dinâmica, logo, as pessoas também terão que ser”.

Ainda em relação ao tempo, o diretor de outra área confirmou que vive "para apagar incêndios porque as pessoas realmente têm dificuldade para identificar o que é urgente, o que é importante daquilo que pode ser aguardado".

Muitas vezes, segundo esse diretor, "num pequeno trajeto caminhado, pode-se conseguir muitos novos problemas, simplesmente encontrando as pessoas pelo caminho". Porém, o diretor considera de fundamental importância dar atenção às pessoas, porque, se, para elas, trata-se de algo urgente, talvez, realmente, sob seu ponto de vista, seja urgente. Isso tudo foi mais intenso no início da carreira desse diretor, porque, com o tempo, passou a ter 
mais familiaridade e já consegue, na medida do possível, identificar a urgência. Para facilitar a administração do tempo do diretor, seriam necessários alguns dispositivos de secretaria para a agenda do mesmo, além do próprio atendimento telefônico.

Por meio do apresentado, nota-se que os diretores não relataram dificuldades de conciliação das atividades de gestão e de docência, como encontrado por Domingues et al. (2009) ao pesquisar coordenadores de curso.

\subsection{COMPROMETIMENTO DOS SUBORDINADOS}

Conforme o relato de um diretor, "a grande maioria dos funcionários preenche as necessidades do departamento, porém falta o comprometimento de uma minoria". Segundo esse entrevistado, no caso de uma reunião de professores previamente agendada que não se realiza pelo não comparecimento dos convocados, as decisões sofrem atrasos e o departamento sofre as consequências; atitudes como estas denotam falta de comprometimento. Segundo o diretor "encontramos pessoas que pensam em si apenas, alguns pensam que se dá aula, dá aula; se é administrativo, é administrativo".

Esse diretor afirma também que "tento conversar, envio comunicação solicitando a colaboração, chamo a chefia para reunião, peço que eles solicitem a presença dos demais. Algumas vezes falo individualmente com muitos desses colaboradores, tento dialogar. Dos mais próximos aos mais distantes, alguns destes não tenho contato frequente, devido ao horário de trabalho". O diretor de centro entende que o chefe de departamento é a sua voz e que, sendo assim, uma solicitação de um chefe é uma solicitação do diretor. Afirma, ainda: "procuro convencê-los de uma forma amigável para que eles possam despertar por interesse, não por obrigação. Nós não entendemos o trabalho como uma obrigação". Silva e Moraes (2003) afirmam, a esse respeito, que um dos aprendizados que os gestores universitários buscam ao longo do exercício da função é o de envolvimento e comprometimento pessoas da IES.

O diretor assim completa o seu relato: "quando o funcionário se envolve e veste a camisa da instituição, tudo funciona melhor, embora esta seja uma expressão desgastada pelo uso. Eu me envolvo com todos os funcionários; para mim, não há hierarquia, eu gosto de uma coisa mais matricial, onde todos conversam, onde todo mundo pede opinião, sem haver distinção de cargo. Eu acho que é por aí que as coisas funcionam, mas tem que haver o comprometimento, tem que estar contente onde ele está". 


\subsection{GESTÃO DE DIVERGÊNCIAS}

Segundo um dos diretores, os problemas de ordem pessoal são os mesmos desde o início de sua gestão (há oito anos), dando principal destaque para os conflitos existentes, que são frequentes. Esses conflitos são entre professores, algumas vezes entre funcionários, mas, seguramente, o maior conflito é entre professores do mesmo curso e, algumas vezes, entre o professor e o chefe de departamento ou, mesmo, com o coordenador do colegiado. Porém, todos os conflitos acabam "caindo na minha mesa", algumas vezes por meio de reclamações, "algumas vezes com pedidos de inquérito ou mesmo depoimentos". Destaca-se que, no estudo de Silva e Moraes (2003), a área de aprendizagem considerada mais importante para o sucesso dos gestores universitários foi a capacidade de lidar com os conflitos e diferenças entre pessoas e grupos.

Segundo esse diretor, a forma como tenta resolver tais conflitos poderá gerar a simpatia ou antipatia nessas pessoas, tornando-se uma situação delicada a ser gerenciada. Destaca que, normalmente, chama as partes envolvidas no conflito e procura ouvir outras pessoas relacionadas à situação, mais especificamente o vice-diretor do centro; outras vezes, um ou mais professores ou, mesmo, em algumas circunstâncias, alunos. Tenta administrar as situações, trazendo as pessoas e conversando. Assim, acaba chegando à conclusão. "Na maioria das vezes, não há necessidade alguma em abrir-se um inquérito porque as pessoas se explicam".

Ainda segundo esse diretor, no ano passado, a maioria dos problemas desse tipo foi resolvida, o que, de certa forma, tornou-se gratificante, porque, se não fosse resolvida, poderia gerar problemas mais sérios. Além disso, aponta que procura adotar uma "política de boa vizinhança, de esclarecimento, procurando ouvir as pessoas, tentando harmonizar umas com as outras".

Existem, também, os conflitos de ordem administrativa, com os chefes de departamentos e com os coordenadores de colegiado, os quais, segundo o diretor, "acham" que podem tudo e, portanto, acabam "querendo" tudo, sem considerarem que, na universidade, existem limitações de orçamento.

Segundo esse diretor, "o maior conflito está relacionado às preferências para alocar recursos financeiros". A demanda é muito grande e, nesse aspecto, os centros de algumas “áreas”, que são consideradas “áreas de ponta, se sobrepõe às demais, têm preferência, não 
vou dizer política, mas político-social”, como, por exemplo, “os projetos de algumas áreas têm muito apoio do governo e dos órgãos privados".

Esse diretor de outra área comenta que "o maior conflito pessoal é tentar fazer com que a minha representação política junto à administração superior encontre o eco mínimo necessário para que eu possa dar conta das demandas que são particulares da nossa unidade". Completa que tem um compromisso diário diante da gestão de não desistir de reivindicar tudo aquilo que é fundamental para o trabalho. Afirmou, ainda, que "por outro lado, tem o aspecto político, qual é a minha participação em termos de peso político na administração”.

Outro diretor destacou: "eu penso que hoje a comunidade a qual represento já tem clareza a respeito do porquê eu me comporto dessa forma. Dentro da unidade universitária, você sempre tem politicamente as oposições naturais que fazem parte do processo democrático. Mas talvez o primeiro impacto que tenha sido causado por essa postura de contestar, pode ter sido negativa; hoje tenho certeza que ela não é. Hoje a maioria dos meus pares entende que a minha perseverança em ficar cobrando a instituição é em prol da nossa comunidade e obviamente sem esquecer a universidade como um todo". Esse diretor completa seu pensamento: "vejo que hoje a comunidade a qual represento, na sua maioria, aceita muito naturalmente essa minha forma de trabalhar".

A respeito dessas necessidades do centro, um diretor ressaltou que é necessário negociar equipamentos (parque tecnológico), laboratórios, verbas, o que, de certa forma, muitas vezes se torna difícil em função do orçamento da IES e da obsolescência rápida que se apresenta em relação à tecnologia.

\subsection{BUROCRACIA E CENTRALIZAÇÃO}

No tocante a essa categoria, um diretor comentou: "os diretores têm um senso de hierarquia e de organização muito grande, atrelado a um senso de organização muito acentuado, o que leva a outra característica que é a centralização". Assim, percebe-se que a burocracia e a centralização caracterizam, também, as direções de centro.

O diretor apontou, ainda, que existe uma hierarquia na IES, segundo a qual as chefias de departamento e as coordenações de colegiados são subordinadas à direção de centro, que , por sua vez, é subordinada às pró-reitorias e à reitoria. Assim, todas as informações que partem da direção de centro, ascendendo ou descendendo na hierarquia, necessitam passar, primeiramente, pelo centro. Além disso, as informações que descendem da reitoria ou das 
pró-reitorias necessitam passar, primeiramente, pela direção para serem transmitidas para as chefias de departamento e para as coordenações de colegiados. Como apontado por Andrade (2002), as decisões são disseminadas ao longo de um grande número de unidades e atores. Walter e Meyer Júnior (2010) acrescentam que cada sistema se apresenta como um sistema parcialmente autônomo de ação, o que faz com que as decisões sejam divulgadas em ritmo mais lento, tornando o sistema menos tangível e mais difícil de ser administrado.

Apesar das críticas a essas características existentes na literatura, esse diretor não considera que a burocracia e centralização sejam prejudiciais à IES. Para ele, consiste em "ter conhecimento das informações que se relacionam com o meu centro. Está vinculada a saber o que está acontecendo e não somente em decidir”. Segundo o diretor, o mesmo precisa ter as informações porque representará professores, alunos e funcionários junto à reitoria, sendo que essas informações necessitam ser confiáveis e verídicas.

Outra forma de centralização e burocracia citada foi a padronização de algumas normas operacionais, a exemplo da política de estágio do centro. O diretor mencionou que sabe que os procedimentos poderiam ser agilizados se não realizasse a centralização das informações da direção de centro, mas acredita que as pessoas poderiam pensar que isso é uma obrigação da direção, já que existe esse cargo para desempenhar tais funções.

\section{8 ÉTICA NOS PROCEDIMENTOS E DECISÕES}

Um dos diretores apontou o desafio de manter a ética na tomada da decisão, visto que, muitas vezes, o diretor tem dificuldade em avaliar todas as consequências possíveis em cada contexto: quando "se tem $100 \%$ de certeza que será para o bem e $0 \%$ para o mal, é fácil tomar uma decisão, mas quando não é dessa forma torna-se complicado”.

Esse diretor relatou que, na tomada de decisões, há que considerar todos esses fatores porque não se trata de agradar a todos, mas ao fato de que as pessoas que elegeram o diretor criam, muitas vezes, expectativas e esperam, realmente, e que a decisão da direção de centro corresponda a sua opinião. Para que isso se amenize, é necessário maior conhecimento a respeito do processo, além das próprias expectativas dessas pessoas.

Outro fator complicador é a urgência de algumas decisões. Segundo esse diretor, porém, é importante ter sempre em mente a preocupação com a ética e aprender a determinar como "urgente" aquilo que realmente é e como importante o que poderá ser mais bem apreciado. 


\section{CONSIDERAÇÕES FINAIS}

Neste estudo, buscou-se analisar os desafios de gestão a partir da percepção de diretores de centro de uma IES pública do sul do Brasil no tocante a conhecimentos; avaliações de outras pessoas; tempo disponível; comprometimento dos subordinados; gestão de divergências; burocracia e centralização; e cuidados éticos.

A esse respeito, alguns dos desafios mais citados estão relacionados aos conhecimentos para o cargo, pois existe, segundo os diretores, uma ausência de informações anteriores acerca de todas as atividades que teriam de assumir no cargo, bem como uma forte demanda de conhecimentos necessários para esse desempenho. Assim, sugere-se que as IES criem mecanismos de difusão de informações a respeito do cargo antes de os diretores o assumirem, bem como disponibilizem meios pelos quais os futuros diretores possam desenvolver habilidades relacionadas à gestão. Nesse sentido, é importante que as IES se voltem para o desenvolvimento de uma cultura focada na captação, absorção, disseminação e utilização do conhecimento.

As avaliações de desempenho, segundo um dos diretores ocorrem, algumas vezes, em forma de julgamentos, sendo que outras pessoas da IES esperam determinado comportamento ou acreditam que o diretor seja responsável por decisões externas ao seu poder de ação. Apesar de esse não ter sido um desafio recorrentemente citado, sugere-se que as IES e seus diretores criem meios de comunicação entre os integrantes, pois esse tipo de avaliação pode acarretar consequências negativas para o desempenho, bem como ser reflexo da dificuldade de estabelecer um diálogo a respeito das expectativas e do contexto das decisões. Também se considera importante que as IES possuam outro mecanismo de avaliação que contribua para o melhor desempenho dos gestores.

O tempo disponível para as atividades do cargo foi um dos desafios mais indicados pelos gestores, que indicaram como complicadores o número de reuniões e eventos aos quais são convidados; a cobrança por produção científica; o número de portarias a serem lidas; ações emergenciais; e a dificuldade de conciliação com a atuação profissional externa, no caso de um diretor que não é contratado com dedicação exclusiva. Alguns diretores conseguem minimizar esse desafio por meio da delegação de atividades, principalmente ao vice-diretor, procedimento que se sugere seja adotado e incentivado por toda a IES. Além disso, sugere-se que a IES ofereça mecanismos de administração de tempo para seus gestores, 
priorizando as ações mais essenciais durante sua carga horária como diretor e delegando as demais atividades a outros integrantes da IES.

O comprometimento dos integrantes da IES foi apontado, quando existente, como um facilitador da atuação do diretor, visto que, quando todos se envolvem, as atividades fluem rapidamente. Destaca-se que a obtenção de comprometimento é um desafio para diferentes tipos de organizações, mas que necessita ser objeto de ação também das IES.

A gestão de divergências foi outro desafio amplamente citado pelos diretores em três âmbitos: conflitos relacionais entre subordinados que necessitam ser resolvidos com os menos dados possíveis; divergências administrativas, que se referem a pessoas que não concordam com decisões tomadas; e conflito pessoal, em relação a seu papel como diretor na IES, principalmente no tocante a ser representativo junto à administração superior e buscar atender às demandas do centro.

A categoria burocracia e centralização não foi apontada pelos diretores como um desafio a ser superado, mas como uma necessidade da IES para respeitar a hierarquia para que os responsáveis por cada nível estejam informados.

Por fim, a respeito dos cuidados éticos, um dos diretores apresentou como desafio manter em mente essa preocupação, mesmo diante de decisões urgentes e da dificuldade para avaliar todas as possíveis consequências de cada decisão em cada contexto.

A partir do apresentado, conclui-se que os principais desafios enfrentados pelos diretores de centro estão relacionados à ausência de conhecimento prévio sobre a função e sobre aspectos de gestão; ao tempo disponível para o cargo em relação ao número de atividades que necessitam ser realizadas; e à gestão de divergências relacionais de subordinados, administrativas e pessoais.

Assim, espera-se que este estudo possa contribuir para a gestão de instituições de ensino ao apontar alguns dos desafios enfrentados por gestores universitários no exercício de sua função, auxiliando os gestores e as IES a melhorarem seus processos de preparação e acompanhamento desses profissionais. Além disso, acredita-se que se possa contribuir com a área de conhecimento ao identificar diferentes desafios e, portanto, diferentes possibilidades de temas de pesquisa em gestão universitária.

Para futura pesquisa, sugere-se analisar como os gestores universitários procuram conciliar suas atividades de gestão e de docência (além de outras atividades), visto que, ao contrário do identificado em estudos anteriores, os gestores pesquisados não a apontaram 
como um desafio. Sugere-se, também, avaliar as reais consequências da burocracia e da centralização na eficácia das IES, uma vez que os gestores pesquisados não as consideraram como prejudiciais à sua gestão.

\section{REFERÊNCIAS}

BITENCOURT, Cláudia Cristina. A gestão de competências gerenciais: a contribuição da aprendizagem organizacional. Tese (Doutorado) - Universidade Federal do Rio Grande do Sul, Programa de Pós-Graduação em Administração. Porto Alegre, 2001. 320 f. Disponível em: <http://www.lume.ufrgs.br/handle/10183/1793>. Acesso em: 9 set. 2010.

BRANDÃO, Hugo Pena. Aprendizagem, contexto, competência e desempenho: um estudo multinível. Tese (Doutorado) - Universidade de Brasília, Programa de Pós-Graduação em Psicologia Social, do Trabalho e das Organizações. Brasília, 2009. 363 f. Disponível em: $<$ http://www.dominiopublico.gov.br/pesquisa/DetalheObraForm.do?select_action=\&co_obra $=163134>$. Acesso em: 20 abr. 2011 .

BRANDÃO, Hugo Pena; GUIMARÃES, Tomás de Aquino. Gestão de competências e gestão de desempenho: tecnologias distintas ou instrumentos de um mesmo construto? Organização, recursos humanos e planejamento. Revista de Administração de Empresas, São Paulo, v. 41, n. 1, p. 8-15, 2001. Disponível em: $<$ http://fortium.edu.br/blog/valeria_martins/files/2010/10/Compet\%C3\%AAncia-edesempenho.pdf>. Acesso em: 2 mar. 2011.

BRASIL. Constituição (1988). Constituição da República Federativa do Brasil. Brasília, DF: Centro Gráfico do Senado Federal, 1988.

CHARLE, Christophe, VERGER, Jacques. História das universidades. São Paulo: Editora da UNESP, 1996.

ENAP - ESCOLA NACIONAL DE ADMINISTRAÇÃO PÚBLICA. Politica Nacional de Desenvolvimento de Pessoal. 2011. Disponível em:

$<$ http://www.enap.gov.br/downloads/pndp.pdf> Acesso em: 9 maio 2011.

FISCHER, André Luiz; DUTRA, Joel Souza; NAKATA, Lina Eiko; RUAS, Roberto.

Absorção do conceito de competência em gestão de pessoas: a percepção dos profissionais e as orientações adotadas pelas empresas. In: DUTRA, Joel Souza; FLEURY, Maria Tereza Leme; RUAS, Roberto Lima (Orgs). Competências: conceitos, métodos e experiências. São Paulo: Atlas, 2008.

GIL, Antonio Carlos. Como elaborar projetos de pesquisa. São Paulo: Atlas, 2002.

GIRARDI, Dante Marciano et al. Considerações sobre a importância da aplicação da teoria dos sistemas nos processos de gestão de pessoas nas universidades: um estudo de caso na UFFS. In: X COLÓQUIO INTERNACIONAL SOBRE GESTÃO UNIVERSITÁRIA NA AMÉRICA DO SUL. Anais, 2010, Mar del Plata. Disponível em:< 
http://www.inpeau.ufsc.br/wp/wp-content/BD_documentos/coloquio10/192.pdf > Acesso em: 10 de maio.

GRILLO, A. N. Gestão de pessoas: princípios que mudam a administração universitária. Florianópolis: [s.n.], 2001.

MAXIMIANO, Antonio Cesar Amaru. Introdução à administração. 6. ed. São Paulo: Atlas, 2004.

MINTZBERG, Henry.O trabalho do executivo: o folclore e o fato. São Paulo: Nova Cultural, 1986.

PESSOA, Maria Naiula Monteiro. Gestão das universidades federais brasileiras: um modelo fundamentado no Balanced Scorecard. Tese (Doutorado) - Universidade Federal de Santa Catarina, Programa de Pós-Graduação em Engenharia da Produção. Florianópolis, 2000. 304 f. Disponível em: <http://www.tede.ufsc.br/teses/PEPS1190.pdf>. Acesso em: 3 out. 2010.

RUAS, Roberto Lima. Gestão por competências: uma contribuição à estratégia das organizações. In: RUAS, Roberto Lima; ANTONELLO, Claudia Simone; BOFF, Luiz Henrique (Orgs.). Aprendizagem organizacional e competências. Porto Alegre: Bookman, 2005.

RUTH, Damian. Frameworks of managerial competence: limits, problems and suggestions. Journal of European Industrial Training, v. 30, n. 3, p. 206-226, 2006. Disponível em: $<$ http://www.emeraldinsight.com/journals.htm?articleid=1550594\&show=abstract $>$ Acesso em: 10 de maio de 2011.

SCHLEMPER JUNIOR, Bruno R. Universidade e sociedade. In: VAHL,Teodoro Rogério; JUNIOR, Victor Meyer; FINGER, Almeri Paulo (Orgs.). Desafios da administração universitária. Florianópolis: Editora da UFSC, 1989.

TOSTA, Humberto Tonani. Competências gerenciais requeridas aos gestores intermediários da Universidade Federal da Fronteira Sul. Dissertação (Mestrado em Administração) Universidade Federal de Santa Catarina, Programa de Pós-Graduação em Administração. Florianópolis, 2011. $143 \mathrm{f}$.

TREVIZAN, Maria Júlia. Competências dos gestores administrativos e de apoio em Universidades Comunitárias. Tese (Doutorado) - Universidade Federal de Santa Catarina, Programa de Pós-Graduação em Engenharia da Produção. Florianópolis, 2004. 190 f. Disponível em: $<$ http://www.tede.ufsc.br/teses/PEPS4057.pdf $>$. Acesso em: 10 set. 2010.

TRIVIÑOS, Augusto N. S. Introdução à pesquisa em ciências sociais. São Paulo: Atlas, 2009.

ZABOT, João Batista M.; SILVA, L.C. Mello. Gestão do conhecimento: aprendizagem e tecnologia construindo a inteligência coletiva. São Paulo: Atlas, 2002. 
ZAINKO, Maria Amelia Sabbag. Planejamento, universidade e modernidade. Curitiba: All Graf, 1998.

ZARIFIAN, Philippe. Objetivo competência: por uma nova lógica. São Paulo: Atlas, 2008. 